\title{
A construção de
} Fernando Haddad em grupos bolsonaristas de WhatsApp na campanha eleitoral de 2018

\section{The construction of Fernando Haddad in WhatsApp bolsonarist groups in the 2018 electoral campaign}

Lucas Moreira VIANA (UNILAB) lucasdfmv@gmail.com

Maria Leidiane TAVARES (UNILAB) marialeidiane@unilab.edu.br

Recebido em: 07 de fev. de 2021. Aceito em: 17 de set. de 2021.
VIANA, Lucas Moreira; TAVARES, Maria Leidiane. A construção de Fernando Haddad em grupos bolsonaristas de WhatsApp na campanha eleitoral de 2018. Entrepalavras, Fortaleza, V. 11, n. 3, e2347, p. 317-334, set.-dez./2021 DOI: $10.22168 / 2237-6321-32347$.

Resumo: Este trabalho visa analisar como é construída a personagem do então candidato à presidência Fernando Haddad nas mensagens compartilhadas em grupos de apoiadores do candidato Jair Bolsonaro no aplicativo de mensagens instantâneas WhatsApp, durante o período de 1 de abril de 2018 a 31 de dezembro de 2018. Partindo dos pressupostos da Teoria Semiolinguística (CHARAUDEAU, 2010), analisamos dados coletados através de uma ferramenta chamada Monitor de WhatsApp. A mensagens coletadas referem-se à construção de Fernando Haddad como antagonista de Bolsonaro e se pretendem discursos midiáticos e informativos autênticos, com o interesse de causar certos efeitos no leitor, identificado aqui como o potencial eleitor. Assim, os resultados apontam para a emergência de um conflito entre supostos ideais de esquerda e direita. Nesse conflito, Jair Bolsonaro é construído como protagonista, através de uma imagem de herói da pátria. Para isso, é utilizado um discurso de glorificação, por meio da visada de páthos, ao tentar causar no leitor os sentimentos de patriotismo e esperança. Fernando Haddad, por sua vez, é construído como antagonista, mediante o uso de visadas incitativas, que tentam 
V. $11(3)$ 317-334 set-dez 2021

convencer o leitor de determinadas informações e, também, da visada de páthos que, ao contrário do uso anterior, é utilizada para causar o sentimento de repúdio.

Palavras-chave: Desinformação. Fake News. WhatsApp. Fernando Haddad.

Abstract: This work aims to analyze how the character of the then presidential candidate Fernando Haddad is built in messages shared in groups of supporters of candidate Jair Bolsonaro in the WhatsApp instant messaging application, during the period from April 1, 2018 to December 31, 2018. Based on the assumptions of the Semiolinguistic theory (CHARAUDEAU, 2010), we analyze the data collected through a tool called WhatsApp Monitor. The messages collected regard the construction of Fernando Haddad as an antagonist of Bolsonaro and are intended as media discourse and authentic newsletters, with the interest of causing certain effects on the reader, identified here as the potential voter. Thus, the results point to the emergence of a conflict between supposed left and right ideals. In this conflict, Jair Bolsonaro is constructed as the protagonist, through an image of a hero of the country. For which a speech of glorification is used, through the vision of pathos, trying to cause in the reader feelings of patriotism and hope. Fernando Haddad, in turn, is constructed as an antagonist, through the use of inciting aims, which try to convince the reader of certain information and, also, of the pathos aim which, unlike the previous use, is used to cause the feeling of repudiation.

Keywords: Disinformation. Fake News. WhatsApp. Fernando Haddad.

\section{Introdução}

O termo desinformação se refere ao ato de compartilhar informações falsas ou duvidosas com a intenção de induzir o outro à crença em determinado fato ou ao erro, ou seja, à criação e difusão deliberada de informação que se sabe ser falsa (cf. WARDLE, 2016). O termo reflete um dos desdobramentos do que se chama de Era da Pós-verdade, que é definida por Conde (2018, p. 15), em tradução à definição dada pelo dicionário de Oxford, como "relativo a ou que denota circunstâncias nas quais fatos objetivos são menos influenciadores na formação da opinião pública que apelo à emoção ou à crença pessoal". Nesse sentido, enunciados que são construídos com o intuito de afetar o emocional do leitor tendem a ser melhor aceitos do que enunciados construídos com base em fatos ${ }^{1}$. Assim, uma notícia que apresenta algo em que o leitor acredita ou que ele quer que aconteça, mesmo que não reflita uma realidade objetivamente verificável, tem maior valor de verdade do que uma notícia baseada em informações cuja apuração apontaria para evidências de efeito de verdade, mas que apresenta algo que vai de encontro ao posicionamento desse sujeito.

\footnotetext{
${ }^{1}$ Não faz parte do escopo do presente texto discutir as noções de fato e verdade, dados os limites de caracteres que temos para desenvolver a discussão proposta. Recomendamos, no entanto, a leitura de Alves e Maciel (2020), que contextualiza tais categorias tendo em vista o trabalho de apuração jornalística.
} 
Uma das manifestações do discurso de desinformação são as chamadas fake news. Essas produções textuais, em geral, são utilizadas para disseminar informações falsas em conformidade com determinados posicionamentos ideológicos de $\mathrm{A}$ ou $\mathrm{B}$, a fim de convencer o leitor da suposta veracidade de determinado fato por meio da simulação do discurso jornalístico.

Conforme Pena (2018), o termofakenews pode ser compreendido em três acepções: na primeira, fake news corresponde a uma estratégia para o controle das mídias de um país. Aqui destacamos o caso da Rússia, entre 2000 e 2008, quando Putin, então presidente russo, "agarrou a mídia como seu utensílio político [...]. Putin marginalizou a mídia impressa em favor da televisiva [...] em favor de exercer maior controle sobre a mídia" (PENA, 2018, p. 139). Criou-se, então, uma rede de manipulação midiática que buscava extinguir as mídias locais para a criação de uma rede nacional controlada pelo governo, que proibia qualquer forma de crítica à gestão, criando notícias positivas sobre o país. Esse movimento ficou conhecido como fake news. O termo ganhava o significado de controle da mídia e da opinião pública. Na segunda acepção, o termo é compreendido, literalmente, como a veiculação de notícias que simulam o gênero jornalístico. Essa acepção ganhou força durante o processo eleitoral estadunidense de 2016. Como afirma Pena (2018), a vitória de Donald Trump sobre Hillary Clinton é atribuída, em parte, ao vazamento de $e$-mails da candidata democrata e à interferência das fake news provindas de território russo. Pena (2018, p. 140-141) afirma que "De acordo com alguns comentaristas, Donald Trump não teria sido eleito se não fossem as Fake News compartilhadas em seu apoio". Na terceira acepção, o termo é entendido como sinônimo de boato, ou seja, conteúdo desinformador deliberadamente divulgado, com informações "comumente usadas como forma de manipular as massas e suas opiniões públicas em encontro de um interesse político específico" (PENA, 2018, p. 136). Essa acepção pode ser exemplificada pelo processo eleitoral de 2018, no Brasil, cerne da discussão feita no presente trabalho, onde o termo fake news passou a ser utilizado para definir quaisquer discursos de desinformação que buscassem manipular a opinião de um terceiro.

Nesse sentido, tendo em vista que tal circulação de informações é circunscrita ao contrato de comunicação que define o estatuto dos participantes da interação discursiva, nosso objetivo é analisar como é feita a construção da personagem do candidato do PT 
V. 11 (3) 317-334 set-dez 2021
Fernando Haddad nas fake news (boatos) veiculadas pelos apoiadores do candidato do PSL Jair Bolsonaro, em grupos do mensageiro instantâneo WhatsApp. Para tanto, iremos verificar as estratégias discursivas usadas para o convencimento do eleitor de que aquele não é um candidato digno de apoio em mensagens que se pretendem discursos autênticos, detentores de informações factualmente verificáveis. Para nossa análise, utilizaremos, fundamentalmente, os estudos de Patrick Charaudeau (2010), que apresentaremos na próxima seção, e em seguida, iremos expor os procedimentos metodológicos adotados, os resultados e as considerações finais sobre esse estudo.

\section{Fundamentação teórica}

Para iniciarmos a discussão acerca das fake news, devemos rememorar o que Charaudeau (2010) chama de "contrato de informação midiático", que compreende a identidade das instâncias de informação, a finalidade do contrato e as circunstâncias das informações.

Charaudeau (2010) considera que os discursos, ao se pretenderem de interesse social, surgem apenas a partir de condições específicas de produção, que se realizam a partir de situações de trocas entre interlocutores. Essas situações configuram um quadro de referências ao qual os indivíduos de dada comunidade retornam ao iniciar um ato comunicativo. Para Charaudeau (2010, p. 67), a situação de comunicação é "como um palco, com suas restrições de espaço, de tempo, de relações, de palavras, no qual se encenam as trocas sociais e aquilo que constitui o seu valor simbólico". As restrições citadas pelo autor seriam estabelecidas por meio de práticas sociais, instauradas pelos indivíduos que vivem em sociedade através de seus discursos. Sob essas restrições, um indivíduo que deseje performar um ato interativo deve submeter-se às configurações pré-estabelecidas por dada sociedade, além de presumir que seu interlocutor possui a capacidade de reconhecer essas configurações.

Charaudeau (2010) utiliza essa metáfora também para explicar o que chama de cointencionalidade. Nos termos do autor, "toda troca linguageira se realiza num quadro de cointencionalidade, cuja garantia são as restrições da situação da comunicação" (CHARAUDEAU, 2010, p. 68). O interlocutor deve considerar que seu parceiro na interação possuirá ou não conhecimento de determinadas informações, ou restrições, para nos mantermos fiéis à obra que fundamenta este trabalho. Assim, o ato 
de escrita (e, por extensão, o ato comunicativo) parte de um contrato de reconhecimento das condições de realização da troca linguageira, resultante de características externas e internas à língua.

Os dados externos são aqueles construídos pelo comportamento das sociedades no que se refere à troca de informações e aos discursos de representação. Esses dados não tendem a ser de origem linguística². Charaudeau agrupa esses dados em quatro categorias definidas pelas condições de produção. A condição de identidade é referente aos participantes do ato de troca quanto à idade, sexo, condição social, etnia etc., enquanto a condição de finalidade refere-se ao objetivo, o motivo da realização de determinado ato comunicativo. Essa condição é marcada pela intenção de fazer com que o interlocutor adira à intencionalidade do discurso, assim utilizando o que Charaudeau (2010) chama de visadas. Essas intenções, por sua vez, podem ser prescritivas, quando o objetivo é convencer o outro a agir de determinada forma; informativas, quando o objetivo é transmitir um saber; incitativas, quando o objetivo é convencer o outro de que o que se diz é verdadeiro, e "do páthos", quando o objetivo é provocar um sentimento no outro. Somam-se, ainda, às condições mencionadas, a condição de propósito, referente à criação de um domínio de saber, isto é, à temática do que é dito, e a condição de dispositivo, referente às condições de produção do discurso - onde o discurso está inserido, como é veiculado.

Os dados internos são os discursivos, referentes a como o discurso deve ser realizado. Quando consideramos os dados externos, devem ser definidos os comportamentos, o modo de falar, a forma verbal e os papéis assumidos pelos interlocutores. Assim, o comportamento linguageiro é dividido em três espaços: o espaço de locução, onde o sujeito deve justificar o motivo pelo qual tomou a palavra, impondose como sujeito falante e identificando seu interlocutor/destinatário; o espaço de relação, onde, ao construir a identidade de seu interlocutor e a sua, o sujeito estabelece relações de "força ou de aliança, de exclusão ou de inclusão, de agressão ou de conivência com o interlocutor" (CHARAUDEAU, 2010, p.71) e o espaço de tematização, onde se determina o domínio do saber e o tema da troca.

Partindo para a comunicação midiática, Charaudeau estabelece a relação entre a instância de produção (a partir de agora chamada de mídia) e a instância de recepção (a partir de agora chamada de público).

${ }^{2}$ Relativos às regularidades comportamentais de indivíduos que efetuam trocas e às constantes que caracterizam essas trocas. 
v. 11 (3) 317-334 set-dez 2021

A primeira teria o papel de fornecedor de informação e de propulsor do desejo de consumir informação. À segunda cabe a função de manifestar seu interesse e/ou prazer no consumo de informações. Charaudeau admite que, em um contexto real, o cenário não é tão utópico, já que à mídia cabe não só fornecer informação, mas "confrontar os acontecimentos que se produzem no mundo ou inteirar-se de sua existência, e de construir, a esse respeito, um certo saber" (CHARAUDEAU, 2010, p. 72).

O público, por sua vez, não se deixa convencer tão facilmente pela instância midiática. Devido à imprevisibilidade do público, que não oferece acesso imediato a suas reações, opiniões e pontos de vista, a mídia parte para a utilização do "destinatário-alvo", caracterizado por um "conjunto 'impreciso' de valores ético-sociais" (CHARAUDEAU, 2010, p.79) que possibilitam estimar os perfis do público a ser atingido. Assim, passamos a ter dois alvos ideais: o alvo intelectivo e o alvo afetivo.

O alvo intelectivo é visto pela mídia como capaz de avaliar seu interesse em relação àquilo que lhe é proposto, de avaliar a entidade que oferece a informação e de conferir-lhe credibilidade. Basicamente, é aquele entendido como dotado da capacidade de pensar, de verificar e julgar o que lhe é mostrado como verdadeiro ou falso. $\mathrm{O}$ alvo afetivo, por sua vez, é entendido como aquele que não é capaz de julgar nada de maneira racional, mas, inconscientemente, apenas de forma emocional. Para atingir esse efeito, a mídia se baseia no que Charaudeau chama de "categorias socialmente codificadas de representação das emoções" (CHARAUDEAU, 2010, p. 82), utilizando estratégias, como o inesperado, que busca romper com o previsível; o repetitivo, que insiste em um fato negativo com o interesse de causar repulsa; o insólito, que aponta fatos incomuns aos costumes sociais de dada comunidade; o inaudito, que tenta levar o leitor ao contato com o sagrado; o enorme, que transforma o leitor no organizador das dimensões do que é comunicado; e o trágico, que fala sobre o destino impossível do homem.

Assim, a finalidade do contrato midiático passa a ser entendida a partir de duas visadas: a de fazer saber, que já abordamos anteriormente, e a de fazer sentir, que teria aqui um objetivo um pouco mais comercial do que aquela, já que busca seduzir as massas para vencer a concorrência. A visada da informação pode ser realizada através de duas estratégias: a descrição-narrativa, em que são reportados os fatos do mundo; e a explicação, em que são esclarecidas para o leitor a informação, as causas e as consequências desses fatos. No entanto, Charaudeau acredita que 
tratar da verdade não é fácil. Para ele, no domínio linguístico, existem maneiras de significar o verdadeiro e de significar o falso. O verdadeiro seria: dizer o que é exato; dizer o que aconteceu; dizer a intenção oculta e fornecer a prova das explicações. O falso seria: dizer o erro; inventar o que não aconteceu; ocultar a intenção e não fornecer provas.

O propósito da informação é entendido por Charaudeau como "aquilo de que se fala, o que está num ato de comunicação" (CHARAUDEAU, 2010, p. 94). Para ele, o conteúdo da notícia é recebido de diferentes maneiras, a depender de quem o recebe e em quais circunstâncias. A exemplo, um acidente de avião pode ser entendido pela empresa responsável como um acidente, mas, pelas famílias das vítimas, pode ser visto como um ato criminoso. A finalidade passa a ser vinculada ao "universo de discurso" ao qual se refere o aspecto referencial da linguagem, além de um ato de troca, pois esse universo é construído através de um recorte do mundo e de representações linguísticas que o reconfiguram em categorias de sentido. Para Charaudeau, este é o processo de "tematização" - um processo de construção dos enunciados, no qual existe um "mundo a comentar" e um "mundo comentado". O primeiro é o mundo em si. O segundo é a representação desse mundo através de um sujeito enunciativo que tem por interesse descrevê-lo ao seu público-alvo.

Todos os atos de comunicação estão limitados pelo dispositivo em que estão inseridos. O dispositivo é

um ou vários tipos de materiais e se constitui como suporte com auxílio de uma certa tecnologia. É no material que se informa, toma corpo e se manifesta [...] o sistema significante: a oralidade, a escrituralidade, a gestualidade, a iconicidade (CHARAUDEAU, 2010, p. 105) [grifo do autor].

A seguir, discorreremos sobre como Charaudeau (2010) apresenta as vantagens e desvantagens de cada um dos dispositivos existentes no momento de escrita da obra. Quanto ao tempo, o rádio era o que permitia difundir a informação mais perto do acontecimento. Quanto ao espaço, o rádio abole a distância entre a mídia e o ouvinte, utilizando-se de um contato direto com a audiência através de cartas, telefonemas etc. Quanto à recepção, ao empregar a oralidade, o rádio cria uma cena de descrição dos acontecimentos e uma cena de troca de opiniões. A televisão, por sua vez, através do uso da imagem, produz três tipos de efeito: um efeito de realidade, quando reporta exatamente o que acontece; um efeito de ficção, quando representa, mediante 
V. 11 (3) 317-334 set-dez 2021

reconstituição, um acontecimento passado; e um efeito de verdade, quando torna visível o que não era, por meio de mapas, gráficos etc. Quanto ao tempo, a televisão tem dificuldade em aproximar o momento da informação do momento do acontecimento, criando, em geral, uma transmissão não direta. Essas condições passam a ser ignoradas em transmissões ao vivo. Quanto ao espaço, a televisão pode criar uma ilusão de contato entre mídia e público, ao, por exemplo, posicionar a câmera exatamente à frente do âncora. Ademais, pode valer-se das mesmas estratégias do rádio para interação com o público.

A mídia impressa, quanto ao tempo, é a que possui o período mais longo entre o momento do acontecimento e o momento da informação, possuindo também uma baixa relação com seu público, mas se mantendo relevante pelo aprofundamento das informações transmitidas.

Sobre as mídias digitais, não citadas por Charaudeau e objeto deste estudo, entendemos que, quanto ao tempo, elas permitem acesso imediato ao acontecimento, superando o rádio, que, para o autor, era a mídia mais rápida até então. Quanto à distância, as mídias digitais permitem acesso imediato à reação do público por meio da caixa de comentários, no caso de sites de notícias. Quanto ao espaço, as mídias virtuais podem utilizar as estratégias de todas as mídias antigas, visto que estabelecem comunicação por texto - em artigos -, por áudio - em podcasts -, e por imagem - em vídeos.

Refletindo brevemente sobre as mensagens compartilhadas no aplicativo WhatsApp é é preciso considerar a dinamicidade da circulação de informações que caracterizam essa mídia, o que pode ser um elemento que dificulta a busca pela verificação da veracidade dos conteúdos ali distribuídos. Como os interlocutores no WhatsApp são, normalmente, indivíduos conectados em redes de confiança, que se conhecem entre si, há a tendência de considerar que o que circula por ali é verdadeiro. O contexto de desinformação compartilhada deliberadamente para fins políticos, somado à possibilidade de valer-se dessa dinamicidade das redes da web 2.0 e dessa relação de confiança entre os interactantes, contribui para a disseminação de conteúdos desinformadores, que, em última instância, foram fundamentais para a campanha bem-sucedida de muitos candidatos a cargos eletivos no Brasil, sobretudo, na eleição de 2018. Após essa exposição de nossa fundamentação teórica, prosseguiremos com a apresentação das escolhas metodológicas. 


\section{Metodologia}

O trabalho foi realizado a partir da análise do corpus coletado através da ferramenta Monitor de WhatsApp³ ${ }^{3}$ desenvolvida por Fabrício Benevenuto de Souza ${ }^{4}$, junto ao grupo de estudos Eleições sem fake ${ }^{5}$, com o objetivo de auxiliar os usuários de internet a verificar a veracidade de notícias compartilhadas por meio do WhatsApp. A ferramenta funciona como um acervo de mensagens, reunindo textos, vídeos, links e imagens dos grupos aos quais possui acesso.

A ferramenta mostra as mensagens que foram compartilhadas em cada dia do ano, a partir do mês de março de 2018, quando parecem começar as atividades do site. Para a obtenção de nosso corpus, demarcamos a nossa busca entre 1 de abril de 2018 e 31 de dezembro de 2018. Essa data inicial foi escolhida pois, a partir dela, a ferramenta passa a ter um maior número de resultados diários. Antes dessa data, o Monitor apresentava espaço de dias entre os resultados. A data final foi escolhida por já compreender a eleição de Jair Bolsonaro, mas não a posse do cargo, possibilitando resultados que ora comemoravam sua vitória, ora versavam sobre o futuro. Selecionamos as mensagens que buscavam: a) convencer o leitor a votar em Jair Bolsonaro; b) construir para Jair Bolsonaro uma imagem herói da pátria; c) criar um embate entre bem e mal opondo as personagens de Jair Bolsonaro e Fernando Haddad; d) desvalorizar Fernando Haddad ou seu partido, visto que, até certo ponto da campanha eleitoral, este não era o candidato do PT.

Assim, de quatrocentas mensagens, trinta e três foram selecionadas e analisadas no que diz respeito às seguintes categorias propostas por Charaudeau (2010), apresentadas na seção de Fundamentação Teórica deste trabalho: os alvos intelectivo e afetivo

\footnotetext{
${ }^{3}$ Acessível em http://www.whatsapp-monitor.dcc.ufmg.br/brazil/. Os dados de login e senha são fornecidos, após contato prévio, pelo Prof. Dr. Fabrício Benevenuto (UFMG), coordenador do grupo que idealizou e implementou a ferramenta.

4 Fabrício Benevenuto é professor adjunto do Departamento de Ciência da Computação da Universidade Federal de Minas Gerais (UFMG). Ele obteve seu doutorado em Ciência da Computação pela UFMG em 2010 e foi vencedor do prêmio Capes de Teses, edição 2011. Fabrício foi pesquisador visitante no HP research Labs em Palo Alto/CA e no Instituto Max Planck na Alemanha e ocupou o cargo de professor adjunto no departamento de Ciência da Computação da Universidade Federal de Ouro Preto por dois anos, onde coordenou o programa de pósgraduação (informações retiradas de http://lattes.cnpq.br/7014991384513854. Acesso em: 3 de fevereiro de 2021).

5 "Eleições Sem Fake é um projeto de Pesquisa que envolve pesquisadores de Universidades Brasileiras e Internacionais. Com conhecimento nas mais diversas áreas, os pesquisadores tem como objetivo principal trazer transparência na disseminação de conteúdo, seja orgânico ou através de anúncios em redes sociais." (WHATSAPP MONITOR, 2018).
} 
V. 11 (3) 317-334 set-dez 2021 pretendidos pela mídia, a partir da adoção dos efeitos de inesperado, repetitivo, insólito, inaudito, enorme e trágico; as visadas do saber fazer (prescritivas, informativas, incitativas) e do fazer sentir (páthos). Uma vez que os textos coletados são exemplares de discursos de desinformação como uma ferramenta política que tem espaço nas mídias digitais, julgamos importante compreender como o apelo ao interlocutor é constituído, daí a eleição de tais categorias analíticas. Destacamos ainda que, por limitações de espaço, não analisamos em texto todas as mensagens selecionadas, utilizando tão somente as mensagens que melhor representam essas categorias.

Nossa análise partiu de hipóteses que apontam para uma transposição de pessoa à persona que destaca características de cunho duvidoso/indecente. Entendemos que, em geral, os apoiadores do candidato Jair Bolsonaro estão inseridos em um contexto que podemos definir como "tradicional". Assim, com o interesse de desmoralizar o candidato rival, as mensagens apresentam conteúdos que atacam diretamente o caráter de Fernando Haddad. Para isso, este é retratado como o mal a ser combatido, o vilão que deseja destruir os "bons costumes" e a "família tradicional brasileira". Por outro lado, a persona de Jair Bolsonaro é construída como o herói da pátria, o responsável pelo fim do governo de esquerda das últimas duas décadas e pelo reestabelecimento do país como potência. Partimos agora para a exposição da análise realizada.

\section{Análise}

As análises realizadas mostram a ocupação de papéis distintos pelas personagens de Jair Bolsonaro e Fernando Haddad nas mensagens em tela. O primeiro ocupa o papel de protagonista ao ser construído como herói da pátria, responsável pela retomada do país como potência e pela extinção dos males causados por seu rival político. Fernando Haddad, que ocupa a função de antagonista, é construído como destruidor dos bons costumes e dos pontos que são pregados por Jair Bolsonaro.

A intriga incitada pelas mensagens analisadas vai além da disputa entre Jair Bolsonaro e Fernando Haddad, visto que o PT passou por um período de indecisão quanto a quem disputaria a presidência pelo partido. Dessa forma, o real conflito observado no conteúdo das mensagens ocorre entre os ideais defendidos pelo candidato Jair Bolsonaro e os ideais que os defensores de Jair Bolsonaro acreditavam 
ser de esquerda. Com isso, temos um confronto de A e B, manifestado textualmente não só através da disputa entre os dois candidatos, mas, também, das ideias que estes, teoricamente, defendiam. Antes de seguir com a análise, ressaltamos que os candidatos são analisados como personagens da narrativa que as mensagens constroem, não como pessoas no mundo.

Transcrição 1: Mensagem 67 de 499 do período de 1 de abril de 2018 a 31 de dezembro de 2018.

Comparativo dos principais tópicos dos programas de governo de Bolsonaro e Haddad (*LULA*), sem interpretações ou opiniões que tendencies para algum dos lados: *IMPOSTOS* - Bolsonaro: Redução da carga tributária e aumento da receita destinada aos municípios (pág 58) - Lula/Haddad: Criar imposto sobre a exportação (pág 41), criar imposto sobre lucros e dividendos (pág 42) e aumentar o importo territorial rual ITR para grandes propriedades (pág 56) *IMPRENSA* - Bolsonaro: contrariedade a qualquer regulação ou controle social de mídia (pág 7) - Lula/Haddad: implantar mecanismos de regulação da imprensa e criar uma empresa pública de comunicação para expor o posicionamento do governo (pág 16) *LAVA JATO* - Bolsonaro: a justiça deverá seguir seu rumo sem interferências políticas (pág 15) - Lula/Haddad: promover uma reforma do sitema de justiça para reduzir o poder de investigação do ministério público federal (pág 6, 15) *SEGURANÇA* - Bolsonaro: tolerância zero com o crime (pág 10) e redução da maioridade penal (pág 32) - Lula/Haddd: desmimlitarização das polícias (pág 31) e iluminação com led nas ruas (pág 54)*MINISTÉRIOS* - Bolsonaro: reduzir os 29 ministérios existentes atualmente (pág 17) - Lula/Haddad: Criar 6 novos ministérios (pág 19, 20 e 55) *DITADURAS SOCIALISTAS* - Bolsonaro: deixar de louvar ditaduras assassinas e socialistas (pág 79) - Lula/Haddad: desenvolvimento da infraestrutura de países do Mercosul (Venezuela) (pág 11) *AGRONEGÓCIO* Bolsonaro: Segurança no campo, políticas para consolidar mercado interno, abrir novos mercados externos, melhoria da logística de distribuição (pág 69) - Lula/Haddad: regulação do agronegócio para evitar ampliação de grandes latifundiários. Implantar reforma agrária e distribuir terras ao MST e indígenas (pág 56) *CONSTITUIÇÃO* Bolsonaro: respeito e obediência à constituição (pág 6) - Lula/Haddad: Estabeçecer um novo processo constituinte para aumentar o poder do estado (pág 6) *PRESÍDIOS* - Bolsonaro: Prender e deixar na cadeira quem tiver cometido crimes (pág 30) e acabar com a progressão de e pena e saída temporária (pág 32) - Lula/Haddad: Reduzir a massa carcerária do Brasil através da liberação de presidiários (pág 33) *SINDICATOS* - Bolsonaro: o sindicato deve ser voluntário, contra a obrigatoriedade do imposto sindical (pág 64) - Lula/Haddad: valorização de sindicatos e associações de trabalhadores (pág 40) *DROGAS* - Bolsonaro: Combate à ideologia de liberação irrestrita de drogas ilícitas (pág 26) - Lula/Haddad: Lula/Haddad: promover a descriminalização das drogas (pág 32) Links do TSE para verificarem a fonte: PLANO DO HADDAD: http://divulgacandcontas.tse.jus.br/candidaturas/oficial/2018/ BR/BR/2022802018/280000629808//proposta_1536702143352.pdf PLANO DO BOLSONARO: http://divulgacandcontas.tse.jus.br/candidaturas/oficial/2018/BR/ BR/2022802018/280000614517//proosta_1534284632231.pdf.

O conflito, nesse exemplo, é construído sobre os supostos tópicos de cada governo. Os tópicos vinculados a Jair Bolsonaro são os ditos de boa moral, ligados a valores tradicionalistas, enquanto os tópicos vinculados a Fernando Haddad pendem para decisões que destruiriam essa tradição. É o caso do tópico drogas, em que o autor da 
V. 11 (3) 317-334 set-dez 2021 mensagem apela para o medo ao afirmar que, enquanto Jair Bolsonaro pretenderia combater as drogas ilícitas, Fernando Haddad promoveria a descriminalização das drogas.

Observemos como a construção textual da mensagem busca convencer o que Charaudeau (2010) chama de alvo afetivo ao utilizar, nos tópicos sobre Fernando Haddad, o efeito de repetição, quando insiste em um fato negativo para causar repulsa. Na mensagem, a repetição é utilizada ao referir cenários recorrentes no território nacional que, por certa "soberania" do PT na presidência, podem ser facilmente assumidos como responsabilidade desse partido. Exemplo disso pode ser observado no tópico referente ao sistema carcerário, há muito criticado pela população, seja por ferir os direitos humanos ou por não ser eficiente. Enquanto a proposta de Bolsonaro prevê prisão e permanência, a de Haddad prevê a liberação dos presos para reduzir a massa carcerária. Para tentar atingir o alvo intelectivo, a mensagem contém links, cuja veracidade não pudemos atestar, pois na ferramenta utilizada para a obtenção do corpus desta análise apenas o texto é copiado. Esses links, no entanto, são incluídos nas mensagens apenas para aumentar a credibilidade da notícia para o leitor menos atento.

A função de protagonista é assumida por Jair Bolsonaro, que tem sua imagem construída a partir de um discurso de glorificação através da visada de páthos e dos efeitos de "captura" do alvo afetivo, inaudito e trágico, em elaborações que buscam causar um sentimento de patriotismo e esperança em seu público-alvo. Vejamos o exemplo a seguir:

Transcrição 2: Mensagem 295 de 499 do período de 1 de abril de 2018 a 31 de dezembro de 2018.

Acabo de chegar do futuro para contar pra vocês que a posse de Bolsonaro foi pura emoção!! Estou vindo de julho de 2019 e o país já é outro! Gleise e Haddad foram presos e o PT fechou as portas! Lula foi condenado mais duas vezes. O MST se desbaratou e o Stédile fugiu para o Uruguai. Boulos foi preso mais uma vez e parece que desta vez o bicho pegou. A economia deu um salto, o desemprego caiu, o estatuto do desarmamento foi revisto e a bandidagem parou de assaltar abertamente com medo de ser alvejada pela população e não entram mais na casa de ninguém! Gilmar Mendes foi expulso do STF e Toffoli renunciou por denúncias de corrupção; Com a vacância dos dois, o presidente Bolsonaro nomeou para os cargos de ministro do supremo Sergio Moro e Marcelo Bretas. Aliás. A Lava Jato se tornou uma operação de elite permanente. Outra coisa: aluno agora que maltrata professor é expulso e fichado na polícia e a maioridade penal foi botada ontem e agora é de 15 anos. Bolsonaro é ovacionado aonde vai no Brasil e exterior. É isso, pessoal! Força aí no passado pra vocês. O futuro é promissor. Até lá *Achei muito legal...rs copiei e colei. 
Aqui, há a projeção de um futuro em que Bolsonaro vence a eleição presidencial. Bolsonaro é construído como herói da pátria e da nação, é mostrado como o responsável pelo fim da corrupção e do desemprego e pela melhoria da economia e da segurança pública. Como já dito, a visada de páthos é utilizada, através dos feitos futuros, para causar naqueles que leem a mensagem o sentimento de que Bolsonaro será o herói da nação, apelando ao patriotismo e à esperança no melhoramento dos serviços públicos.

Fernando Haddad, por sua vez, junto do partido que representa, assume a função de antagonista. Sua imagem é construída como a de um mal a ser derrotado pela personagem de Jair Bolsonaro. Se Bolsonaro é mostrado como herói da pátria e da nação, Haddad é mostrado como representante do mal que assola o país. As mensagens voltadas para a construção de Haddad utilizam as visadas incitativas, ao tentarem convencer o leitor da veracidade do fato lido e, como na construção de Bolsonaro, de páthos, ao tentarem causar o sentimento de repúdio no leitor, além do efeito insólito, previsto por Charaudeau (2010) ao referir-se a fatos incomuns aos costumes de uma sociedade. Quanto à figura de Haddad, observemos:

Transcrição 3: Mensagem 95 de 499 do período de 1 de abril de 2018 a 31 de dezembro de 2018.

Que tal estimular *relação entre pai e filha*? Espanto? Esta é a leitura que foi disponibilizada pelo *Ministro de Educação Haddad* enquanto esteve à frente deste ministério. O governo comprou e distribuiu para escolas entre criancinhas um livro em que o pai castiga a filha por "não querer ser dele". Você pensa que já tinha visto de tudo? *Engana-se!!!* Veja a reportagem: is of \& 4 .

Nesse primeiro exemplo, a imagem de Haddad é relacionada a um ato que seria considerado doentio pela maioria dos leitores dessa mensagem. Podemos observar, aqui, a utilização de um elemento recorrente nas construções que buscam atacar Fernando Haddad. A figura da criança é utilizada, de certo modo, como metáfora do corrompimento moral do candidato, que, em geral, é categorizado como imoral frente aos bons costumes pregados pelo seu rival, causando um conflito direto entre as duas personagens, utilizando, de maneira premeditada, "a trama enquanto projeto dramático" (MOTTA, 2013, p. 167, grifo do autor), para o convencimento do leitor que compartilha da opinião do autor da mensagem. Busca-se, como já dito, a repulsa à pessoa através de sua persona, tornando-o ignóbil à opinião pública. 
V. 11 (3) $317-334$ set-dez 2021
Transcrição 4: Mensagem 235 de 499 do período de 1 de abril de 2018 a 31 de dezembro de 2018

Com o apoio do candidato a presidência Fernando Haddad, vou criar a Lei Marielle Franco, essa lei obrigará Padres e Pastores a realizarem cerimônias de casamentos homossexuais na igreja, os que recusarem serão presos - Jean Wyllys https://www. facebook.com/1813304148738231/posts/1837907986277847/;

Nessa mensagem, voltada a um público mais específico, busca-se o convencimento daqueles que são contra o casamento entre homossexuais. Procura-se mostrar que Fernando Haddad é um candidato que se opõe aos seus valores, retratando-o como um revolucionário que busca destruir os "bons princípios". Ressaltamos, nesse exemplo, a presença de uma terceira personagem, Jean Wyllys. O texto da mensagem é uma suposta fala do então deputado federal. A referência a ele revela uma outra constante das mensagens analisadas que, de certo modo, poderiam compor uma quinta categoria, a de conteúdos "antiesquerda".

Por vezes, a construção de Fernando Haddad é realizada de forma a construir uma figura com traços maquiavélicos, através de mensagens que poderiam ter seu valor de verdade questionado por um público mais atento. Porém, considerando a hipótese fraca, proposta por Charaudeau, sobre o baixo grau de criticidade dos receptores da informação, o conteúdo não deixa de convencer alguns leitores por meio da afetividade (daquilo que se espera ser real). A mensagem a seguir demostra essa utilização em um texto quase fabular, junto à "demonização" da esquerda.

Transcrição 5: Mensagem 211 de 499 do período de 1 de abril de 2018 a 31 de dezembro de 2018.

Haddad foi visitar uma escola para conversar com as crianças, acompanhado de uma comitiva. Depois de apresentar todas as maravilhosas propostas para seu governo, disse às crianças que iria responder perguntas. Uma das crianças levantou a mão e Haddad perguntou: - Qual é o seu nome, meu filho? - Paulinho - Qual é a sua pergunta, Paulinho? - Eu tenho 3 perguntas para a senhor: Onde estão os milhões de empregos prometidos na campanha presidencial passada? Quem matou o Prefeito Celso Daniel? e O senhor sabia dos escândalos do mensalão ou não? Haddad fica desnorteado mas, neste momento, toca a campainha para o recreio e ele aproveita e diz que continuará a responder depois do recreio. Após o recreio, o petista diz - OK, onde estávamos? Acho que ia responder perguntas. Quem tem perguntas? Um outro garotinho levanta a mão e o petista aponta para ele. - Pode perguntar meu filho. Como é seu nome? Joãozinho e tenho 5 perguntas. - Quais, Joãozinho? - As perguntas são: Onde estão os milhões de empregos prometidos na campanha presidencial passada?, Quem matou o prefeito Celso Daniel?, O senhor sabia dos escândalos do mensalão ou não?, Por que o sino do recreio tocou meia hora mais cedo? e Cadê o Paulinho? 
Através de uma construção narrativa, utilizando novamente a figura da criança como símbolo de pureza destruída, Fernando Haddad é retratado como "fantasma" das gestões passadas, tendo outra vez atribuída a si a característica de continuador dos males vividos pela população, por meio da estratégia de repetição. Além disso, enfatiza-se a manipulação e a opressão por parte da personagem quando o primeiro garoto lhe que faz as perguntas e Haddad supostamente se esquiva.

As mensagens compartilhadas nos grupos de WhatsApp utilizam a estratégia da explicação, prevista pela visada da informação (CHARAUDEAU, 2010). É perceptível que o texto não busca copiar a escrita midiática tradicional, mas reproduzir a voz de um sujeito qualquer, na maior parte das vezes desconhecido, diminuindo a responsabilidade sobre o que é transmitido.

Transcrição 6: Mensagem 12 de 499 do período de 1 de abril de 2018 a 31 de dezembro de 2018.

REPASSEM PARA O MAIOR NUMERO DE PESSOAS Tudo que a Joice HALSSEMANN falou até agora aconteceu. Então é melhor prevenir do que Remediar! O PT tem uma última carta na manga. Faltando 3 dias para eleições terá um falso ataque contra o Haddad e Manuela. Eles se deixarão bater de verdade até causar ematomas. Esses hematomas e para garantir que a hipótese de que seja mentira seja logo rechaçada. $\mathrm{O}$ suposto agressor será Branco dos olhos azuis e usará uma camisa do Bolsonaro com uma suástica e foto de Hitler. As Mídia cobrirá o caso 24h. O principal rosto a ser mostrado será o de Manuela, Por ser mulher e ter menos rejeição que o Haddad. O caso é colocado em segredo de justiça com justificativa de não interferir nas eleições. O suposto agressor ainda vai alegar que fez a mando do capitão e recebeu ameaça de morte como queima de arquivo. Uma manifestação \#elenão acontecerá no sábado, essa manifestação vai ter o mesmo número da primeira, mas a mídia divulgará como a maior manifestação da história. Todo e qualquer questionamento será rotulado como Fake News (Por isso estão Martelando essa narrativa 24h.) O povo, já sabendo do que vai acontecer, não mudara o voto, mas no sábado o Datafolha e o Ibope colocarão, de forma manipulada, 51\% E 49\% PRO Bolsonaro. Alegando que o povo estava comovido com o caso, causando assim um empate técnico. No domingo as urnas serão manipuladas. $51 \%$ a $49 \%$ para o Haddad, e na mesma hora, e em todos os canais, analistas políticos vão dizer que é normal a vitória pela comoção com a agressão. e questionar o resultado das urnas com Fake News é uma atendado a democracia. Depois não da para imaginar o que acontece. Divulgue o máximo que puder, enquanto ainda é tempo. Se não acontecer, o PT ficou com medo do vazamento do plano causa uma indignação maior do que eles possam suportar, e atrair a fúria do exército. Se o PT tiver coragem e colocar em prática, o povo já vai estar sabendo, e poderá partir para a guerra. O plano foi colocado em público por um rapaz (tem um vídeo circulando na internet). Todo o resto são os desdobramentos naturais que isso tomaria. PESSOAS. https://m.facebook.com/story.php?story_fbid=10205234025447782\&id=1760730201

Expressões como "REPASSEM PARA O MAIOR NÚMERO DE PESSOAS", são as responsáveis por transformar as mensagens em um texto explicativo. Além disso, outras estratégias são utilizadas para que, quando o fato reportado for provado como irreal, a mensagem não perca 
V. 11 (3) 317-334 set-dez 2021 sua credibilidade. Por exemplo, o texto retoma as próprias fake news, como forma de mostrar que a mensagem não é uma delas. Nas últimas linhas, o autor da mensagem afirma que, em caso de o fato reportado não acontecer, a razão para isso é a desistência do PT por medo de retaliação - outra estratégia para não perder a credibilidade do texto.

O cenário construído pelas mensagens busca mostrar Jair Bolsonaro como a melhor opção entre os concorrentes à presidência; para isso, constrói sua figura como a esperança da nação. Fernando Haddad é apresentado como um candidato que não deve ser considerado digno de apoio por possuir ideais diabólicos que destruiriam a nação. Com isso, a intenção geral do quadro enunciativo criado pelas mensagens é buscar apoiadores para o primeiro candidato e incerteza quanto à dignidade e responsabilidade do segundo.

\section{Considerações finais}

A partir da análise do discurso midiático proposta por Charaudeau (2010), tomamos por objeto a construção de Fernando Haddad como antagonista de Jair Bolsonaro nas mensagens compartilhas em grupos de WhatsApp durante o período eleitoral de 2018. Partimos da observação de um quadro temático mobilizado para caracterizar os sujeitos, no qual identificamos o conflito geral das narrativas e as posições ocupadas pelas personagens. Compreendemos, assim, como foi construído o antagonismo entre os candidatos nas mensagens, as quais sedimentaram discursos que produzem efeitos de adesão nos interlocutores.

Dessa forma, nossos resultados apontam para a utilização do que autores como Motta (2013) chamam de intriga, manifestada em texto pela contraposição entre ideais de direita e ideais julgados pelos autores das mensagens como pertencentes à esquerda. Os ideais da direita são atribuídos à personagem de Jair Bolsonaro, que ocupa, no quadro narrativo observado, a função de protagonista. Para isso, são compartilhados discursos que promovem Jair Bolsonaro como herói da pátria, através da produção de efeitos de sentido que podem ser caracterizados a partir do que Charaudeau (2010) chama de visadas e de efeitos de atração do alvo afetivo, ao passo que buscam ludibriar, mobilizando estratégias para a construção de efeitos de real, o alvo intelectivo. Assim, as visadas mais recorrentes que observamos nesses discursos foram: a de páthos, utilizada para causar sentimentos no 
interlocutor, nesse caso, principalmente de esperança e patriotismo, além da visada incitativa, utilizada para convencer o leitor de que as informações passadas são reais. Quanto aos efeitos para atração do alvo afetivo, os mais recorrentes são: o inaudito, quando se mostra ao leitor a uma relação sagrada ao caracterizar a eleição de Jair Bolsonaro como uma missão divina; e o trágico, ao tratar o candidato como predestinado a salvar o país.

Os supostos ideais de esquerda, por sua vez, não se limitam apenas à personagem de Fernando Haddad, haja vista que, nas próprias construções textuais, os alvos se alternam entre Fernando Haddad, PT e membros da esquerda, os quais ocupam, porvezes, a função de personagens que metonimicamente equivalem a todo o espectro político identificado como o de esquerda. Porém, considerando a disputa entre Fernando Haddad e Jair Bolsonaro, entendemos que, mesmo com a ausência de Haddad em determinadas construções, os efeitos causados recaem sobre ele, pois o candidato é entendido como representante momentâneo da esquerda no pleito de 2018. Assim, sua função de antagonista tem como visadas mais recorrentes a de páthos, mas, nesse caso, objetivando um sentimento de repúdio, e as incitativas, buscando convencer o leitor dos fatos reportados. Quanto aos efeitos, são utilizados: o repetitivo, quando as mensagens insistem em condições ruins de determinadas instâncias do país ou quando insistem em falhas dos governos anteriores; o insólito, quando citam "propostas" de Fernando Haddad que vão contra os valores supostamente comuns à sociedade brasileira; e, de certo modo, um efeito não citado por Charaudeau, mas que se apresenta ao nosso ver como contrário ao inaudito, alcançado quando, nos discursos de confronto entre Jair Bolsonaro e Fernando Haddad, o segundo é comparado ao maldito, enquanto o primeiro, ao sagrado.

Por fim, o trabalho abre espaço para a produção de pesquisas futuras, nas quais pode ser aprofundada a construção do conflito narrativo - aqui utilizado apenas como fundo para a obtenção das características das personagens -, e a análise da estrutura linguística e composicional das mensagens, a fim de caracterizar a miríade de textos que podem ser reunidos sob a alcunha de fake news.

\section{Referências}

ALVES, M. A. S.; MACIEL, E. R. H. O fenômeno das fake news: definição combate e contexto. Internet \& Sociedade, n. 1, v. 1, p. 144-171, fev. 2020. Disponível em: https://revista.internetlab.org.br/o-fenomeno-das-fakenews-definicao-combate-e-contexto/. Acesso em: 27 out 2021. 
V. 11 (3) 317-334 set-dez 2021
CHARAUDEAU, P. Discurso das mídias. 2. ed. São Paulo: Contexto, 2010.

CONDE, C. A. G. F. Desinformação: qualidade da informação compartilhada em mídias sociais. 2018. Tese (Doutorado em Ciência da Informação) Universidade Estadual de Londrina, Londrina, 2018.

MOTTA, L. G. Análise crítica da narrativa. Brasília: Editora Universidade de Brasília, 2013.

PENA, L. P. J. Fake news: uma breve análise acerca de sua trajetória internacional, consequências políticas e perspectiva jurídica. Revista Dizer, v. 3, n. 1, 30 dez. 2018.

WARDLE, C. 6 types of misinformation circulated this election season. Columbia Journalism Review. 18 de novembro de 2016. Disponível em: https://www.cjr. org/tow_center/6_types_election_fake_news.php. Acesso em: 4 out 2021. 